\title{
School snacks decrease morbidity in Kenyan schoolchildren: a cluster randomized, controlled feeding intervention trial
}

\author{
Charlotte G Neumann ${ }^{1, *}$, Nimrod $\bigcirc$ Bwibo ${ }^{2}$, Luohua Jiang ${ }^{3,4}$ and Robert E Weiss ${ }^{4}$ \\ 'Departments of Community Health Sciences and Pediatrics, University of California, Los Angeles (UCLA) \\ Fielding School of Public Health and Geffen School of Medicine, PO Box 951772, Los Angeles, CA 90095- \\ 1772, USA: ${ }^{2}$ Department of Paediatrics, Faculty of Medicine, University of Nairobi, Nairobi, Kenya: \\ ${ }^{3}$ Department of Epidemiology and Biostatistics, School of Rural Public Health, Texas A\&M University, College \\ Station, TX, USA: ${ }^{4}$ Department of Biostatistics, UCLA Fielding School of Public Health, Los Angeles, CA, USA
}

Submitted 19 April 2012: Final revision received 12 February 2013: Accepted 20 February 2013: First published online 28 March 2013

\begin{abstract}
Objective: To examine the effects of three different school snacks on morbidity outcomes.

Design: Twelve schools were randomized to either one of three feeding groups or a Control group. There were three schools per group in this cluster randomized trial. Children in feeding group schools received school snacks of a local plant-based dish, githeri, with meat, milk or extra oil added. The oil used was later found to be fortified with retinol. Physical status, food intake and morbidity outcomes were assessed longitudinally over two years.

Setting: Rural Embu District, Kenya, an area with high prevalence of vitamin A deficiency.

Subjects: Standard 1 schoolchildren ( $n$ 902; analytic sample) enrolled in two cohorts from the same schools one year apart.

Results: The Meat and Plain Githeri (i.e. githeri + oil) groups showed the greatest declines in the probability of a morbidity outcome (PMO) for total and severe illnesses, malaria, poor appetite, reduced activity, fever and chills. The Meat group showed significantly greater declines in PMO for gastroenteritis (mainly diarrhoea) and typhoid compared with the Control group, for jaundice compared with the Plain Githeri group, and for skin infection compared with the Milk group. The Milk group showed the greatest decline in PMO for upper respiratory infection. For nearly all morbidity outcomes the Control group had the highest $\mathrm{PMO}$ and the least decline over time.

Conclusions: The intervention study showed beneficial effects of both animalsource foods and of vitamin A-fortified oil on morbidity status.
\end{abstract}

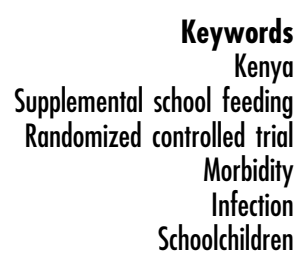

Globally, the negative health consequences of malnutrition and infection are a leading cause of morbidity and mortality in children, contributing to $53 \%$ of all deaths in children under 5 years of age ${ }^{(1-4)}$. Malnutrition is estimated to contribute to $45 \%$ of measles deaths, $52 \%$ in pneumonia, $57 \%$ in malaria and $61 \%$ in diarrhoea ${ }^{(1-4)}$. Few studies have been undertaken in school-aged children. Poverty, lack of health care, high infection burden, diets containing negligible amounts of animal-source foods (ASF) and deficiencies in macro- and micronutrients are contributing factors $^{(4-7)}$. Severe protein-energy malnutrition and coexisting micronutrient deficiencies are associated with decreased immune function ${ }^{(8,9)}$. Children with severe protein-energy malnutrition often have high case fatality rates, particularly from measles, pneumonia, diarrhoea, malaria and tuberculosis ${ }^{(2,4)}$.
Deficiencies of $\mathrm{Fe}, \mathrm{Zn}$, vitamin $\mathrm{A}$ and vitamin $\mathrm{B}_{12}$ can impair cell-mediated immunity and granulocyte function, resulting in disruption of anatomic barriers to pathogens $^{(10-14)}$. Multiple micronutrient fortification of milk has been shown to reduce instances of pneumonia, diarrhoea, measles and high fever ${ }^{(15)}$. Fe and $\mathrm{Zn}$ supplementation decrease risk of severe diarrhoea and acute respiratory infections ${ }^{(16,17)}$, and $\mathrm{Zn}$ and vitamin $\mathrm{A}$ in combination reduce persistent diarrhoea prevalence in children $^{(18)}$. Vitamin A supplementation alone has been shown to decrease mortality ${ }^{(19,20)}$, prevalence of various morbidities $^{(21,22)}$, clinical malaria episodes ${ }^{(23)}$ and diarrhoea severity ${ }^{(24)}$, as well as prevent acute respiratory infections in infants and children ${ }^{(24-26)}$. However, other studies show no effect of vitamin A supplementation on incidence of acute respiratory infections and severity 
or diarrhoea morbidity ${ }^{(19,27)}$. Zn supplementation has been associated with improvements in cell-mediated immunity ${ }^{(28,29)}$ and was effective in treating prolonged bouts of diarrhoea, pneumonia and malaria episodes in malnourished children ${ }^{(30-36)}$.

$\mathrm{Fe}$ and $\mathrm{Zn}$ deficiency may reduce chemotaxis and bactericidal function ${ }^{(37)}$. Combined $\mathrm{Fe}$ and $\mathrm{Zn}$ supplementation in poorly nourished 6-month-old infants resulted in lower risk of developing severe diarrhoea and acute lower respiratory infection ${ }^{(17)}$. Fe-supplemented Sri Lankan children (5-10 years old) experienced fewer upper respiratory infections (URI) and fewer total number of days sick compared with placebo children ${ }^{(38)}$. Fe supplementation can also increase morbidity depending on the host's Fe status. A systematic review of twenty-eight $\mathrm{Fe}$ supplementation studies documented increased risk for developing diarrhoea in Fe-supplemented children but not increased risk for developing overall infection ${ }^{(39)}$. Fe administered to infants with severe protein-energy malnutrition and low transferrin has been associated with acute exacerbations of clinical malaria and increased morbidity from other infectious diseases, attributed to unbound free Fe which enhances bacterial multiplication ${ }^{(37)}$. Fe and riboflavin deficiency may confer protection against clinical malaria, but the evidence is inconclusive ${ }^{(40-42)}$. Fesupplemented pre-school children (aged 1-35 months) in an area with endemic malaria showed an increased risk of death or hospitalization from malarial adverse events ${ }^{(43)}$.

A wide variety of ASF (including blood, offal, fish, insects and molluscs) contain energy, complete protein and micronutrients such as bioavailable $\mathrm{Fe}$ and $\mathrm{Zn}$, vitamin $\mathrm{B}_{12}$ and preformed vitamin $A^{(5)}$. Several food-based ASF interventions have demonstrated reductions in morbidity, namely fever, respiratory and diarrhoeal infections and anaemia $^{(44-46)}$. The current paper reports on the first cluster randomized, controlled feeding intervention to examine the effect of ASF compared with plant-based foods on morbidity outcomes among schoolchildren, an understudied group. It was hypothesized that children in the feeding groups receiving milk or meat would experience fewer and less severe morbidity episodes than children in the Plain Githeri group, receiving the isoenergetic maize/ bean dish, and the Control group. Cluster randomization was chosen for practical reasons as it would have been impossible to prepare and deliver feedings to individual households or to prepare and deliver different feedings within the same school.

\section{Experimental methods}

The study was conducted in rural Embu District, Eastern Province, Kenya, $120 \mathrm{~km}$ north-east of Nairobi. The study area covered $60 \mathrm{~km}^{2}$ with gradients of altitude and rainfall, ranging from a semi-arid area at $1200 \mathrm{~m}$ to an area with greater rainfall at $1500 \mathrm{~m}$. Distinguishable seasons generally included long rains from March to May, short rains from October to November, a warm dry season from January to March, and a cooler dry season from July to September. Universal compulsory primary school education exists in this area, so most children attend at least Standards 1 to 3 of primary school. In the study area households own several goats and chickens, but few own larger animals, and ASF is rarely consumed except for modest amounts of milk and eggs. There is occasional consumption of worms, termites and molluscs, but rarely fish. Intakes of total animal-source protein, protein from meat, fish and poultry, and vitamin A are extremely low ${ }^{(47)}$. Diets contain high levels of fibre and phytate and poorly bioavailable Fe and $\mathrm{Zn}^{(47-49)}$.

\section{Study design}

Twelve of eighteen schools in two sub-locations with $\sim 2600$ households were selected for cluster randomization (Fig. 1). Six schools were initially eliminated because of size and inaccessibility for food delivery due to impassable roads during rainy seasons. Thus, twelve schools were randomized to one of three feeding intervention groups or a Control group, with three schools per each feeding condition. Schools were $\sim 3-5 \mathrm{~km}$ apart with little chance for exposure to each other as the study area was rural with scattered farms, with walking as the main mode of transportation. All Standard 1 classrooms at each school were assigned to the same feeding intervention or to the Control condition.

A second cohort of Standard 1 children was enrolled because a 6-week teacher's strike occurred six weeks after Cohort I enrolment, resulting in disruption of feedings and data collection, and because of a severe, worsening drought. Cohort II was enrolled exactly one year later, with schools assigned to the same feeding group as in Cohort I. Feeding for both cohorts occurred only when school was in session (three terms per year) and no feeding occurred during the one-month school vacations between terms. Feeding took place from September 1998 to December 2000 for Cohort I and from September 1999 to December 2001 for Cohort II.

\section{Participants}

The initial sample of Standard 1 children had 1078 children (554 in Cohort I; 524 in Cohort II). The final analytical sample was 902 children (130 were excluded due to missing data, five died, thirty-three left the study area, and eight were excluded from data collection due to mental or physical handicaps but fed with classmates). Data for children who left the study area remained in the analysis to the point that they moved.

\section{Feeding intervention}

The three supplemented groups received mid-morning 'snacks' at school each school day. The Control group participated in all measurements but did not receive an 


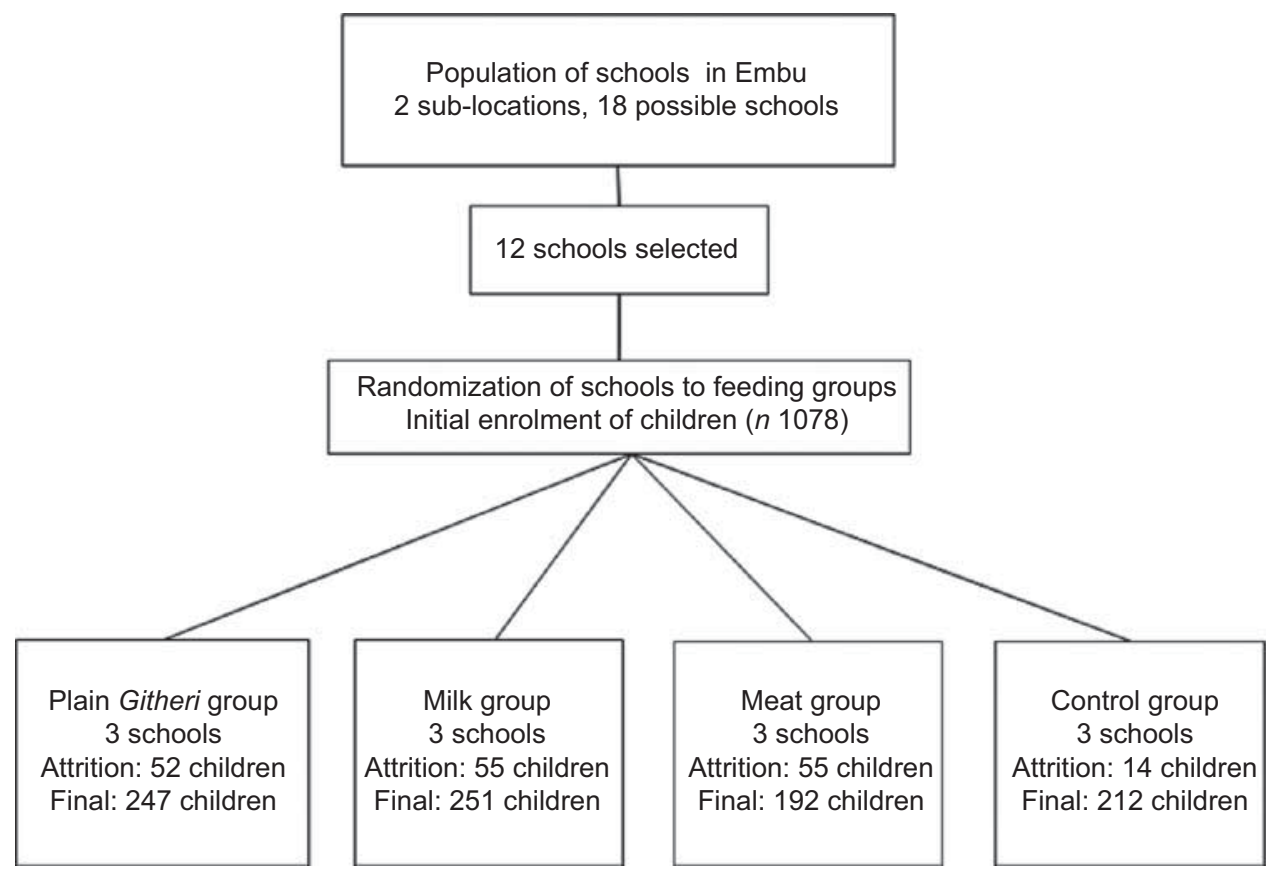

Fig. 1 Trial profile

intervention feeding. School snacks for the intervention groups were based on githeri, a local stew of maize, beans and greens. For the Meat group, finely ground beef with $10-12 \%$ fat was added to githeri. The Milk group received $250 \mathrm{ml}$ of whole ultra-heat-treated (UHT) cow's milk plus githeri. The vitamin $\mathrm{B}_{12}$ content of UHT milk was measured and found comparable to that of pasteurized fresh milk. The Plain Githeri group received githeri with additional oil (Kimbo; Unilever, East African Industries, Nairobi, Kenya) rendering it isoenergetic with the other snacks. Oil was used in the preparation of all three snacks, but the greatest amount of oil was added to the Plain Githeri group $(5 \cdot 2 \mathrm{~g} / \mathrm{snack}$, compared with $3.6 \mathrm{~g} / \mathrm{snack}$ in the Milk snack and $1.6 \mathrm{~g} / \mathrm{snack}$ in the Meat snack). Midway through the study, the oil, which was not originally labelled by the manufacturer as fortified, was discovered to have been fortified with retinol $(37 \mu \mathrm{g}$ retinol/g fat).

Snack ingredients were increased by $\sim 25 \%$ after four months as the children increased in size and because of a persistent drought and food shortages. Snacks contained approximately one-fifth of the recommended daily energy intake for age and gender. Nutrient composition of snacks is summarized in Table 1 and has been described previously ${ }^{(48,49)}$. Milk and beef were familiar and culturally acceptable foods. Children were observed eating the school snack. Their numbered containers were collected and leftovers measured, weighed and recorded. For more than $98 \%$ of feeding sessions, snacks were completely consumed ${ }^{(50)}$. Quality control procedures have been described previously ${ }^{(47)}$.

\section{Child measures}

Initial health histories and physical examinations were carried out by physicians. Splenomegaly, indicative of endemic malaria, was assessed by palpation (measured in $\mathrm{cm}$ below the mid-left costal margin). Nutritional status was assessed by anthropometry and by the presence of signs of nutritional deficiencies ${ }^{(51)}$. Due to funding limitations, serum biochemical analyses for vitamins $\mathrm{A}, \mathrm{B}_{12}$, riboflavin, $\mathrm{Fe}$ and $\mathrm{Zn}$ were performed only at baseline and the end of year one for Cohort I. Analytical methods used have been fully described previously ${ }^{(52)}$. Stool samples were examined for intestinal ova and parasites using the formal-ether sedimentation method and Lugol's stain ${ }^{(53)}$. $\mathrm{Hb}$ was measured using the Hemocue apparatus ${ }^{(54)}$. Malaria antigen dipsticks (Vision Biotech, Cape Town, South Africa) were used to detect Plasmodium falciparum malaria infection, the predominant type in the area, annually and whenever malaria was suspected ${ }^{(55)}$. Clinical diagnoses of typhoid were based on laboratory serologic confirmation tests at the health centre or hospital (Widal titre).

\section{Morbidity assessment}

Morbidity prevalence data were collected by home visits every month for eight months for Cohort I, then every other month thereafter for Cohort I and every second month for both years of Cohort II. Thus, there were fifteen morbidity data collection visits for Cohort I and twelve for Cohort II.

The child's caregiver was asked to describe the child's illness in her own words. Then a structured questionnaire was used to ask about signs and symptoms of illness in 
Table 1 Nutrient content of school snackst

\begin{tabular}{|c|c|c|c|}
\hline & Githeri + Meat & Githeri + Milk & Githeri+ Oil \\
\hline Serving size & $225 \mathrm{~g}$ (includes $85 \mathrm{~g}$ meat) & $100 \mathrm{~g}+250 \mathrm{ml} \mathrm{milk}$ & $230 \mathrm{~g}+3 \cdot 8 \mathrm{~g}$ oil \\
\hline \multicolumn{4}{|c|}{ 2 } \\
\hline $\mathrm{kJ}$ & 1310 & 1310 & 1310 \\
\hline kcal & 313 & 313 & 313 \\
\hline Total protein $(\mathrm{g})$ & $21 \cdot 7$ & $15 \cdot 2$ & 8.4 \\
\hline Total Fe (mg) & 2.94 & 1.57 & 3.93 \\
\hline Available $\mathrm{Fe}(\mathrm{mg}) \ddagger$ & 0.48 & $0 \cdot 10$ & $0 \cdot 20$ \\
\hline Total Zn (mg) & $2 \cdot 89$ & 1.66 & 1.68 \\
\hline Available Zn (mg)‡ & 0.44 & 0.38 & 0.23 \\
\hline Vitamin A ( $\mu \mathrm{q} R E) \S$ & $112 \cdot 0$ & $412 \cdot 0$ & $364 \cdot 0$ \\
\hline Vitamin A from commercial oil ( $\mu \mathrm{g} R E) \|$ & $59 \cdot 2$ & $133 \cdot 2$ & $192 \cdot 4$ \\
\hline Vitamin $B_{12}(\mu \mathrm{g})$ & 0.91 & $1 \cdot 16$ & 0.0 \\
\hline
\end{tabular}

$\mathrm{RE}$, retinol equivalents.

Modified from Neumann et al. ${ }^{(64)}$

tThe nutrient content presented in this table reflects the increase of $25 \%$ of the initial recipe that occurred after 3 months of the study because of a prolonged drought and food shortage in the study area.

$\ddagger$ Availability of the snack's Fe and $\mathrm{Zn}$ is assumed to be equal to the average availability across the day's intake $(9 \%$ and $13 \%$ for Fe and $\mathrm{Zn}$, respectively). If the snack is consumed alone, availability would be higher for the meat snack; available Fe would be $\sim 0.53$ mg and available $\mathrm{Zn} \sim 1.36 \mathrm{mg}$. The snack was consumed alone almost all of the time.

$\S$ This value reflects the amount of vitamin A originally calculated based on the known ingredients using the WorldFood 2 Dietary Assessment Program and analyses of known ingredients by Medallion Laboratories. This value does not include the retinol from the commercial oil added to make snacks isoenergetic. This oil was not labelled as retinol-fortified by the manufacturer (Unilever, East African Industries, Nairobi, Kenya) until some time after the study began.

$\|$ This value reflects the amount of vitamin A from the oil. This oil was not labelled as retinol-fortified by the manufacturer until some time after the study began.

Table 2 Morbidity outcome variables

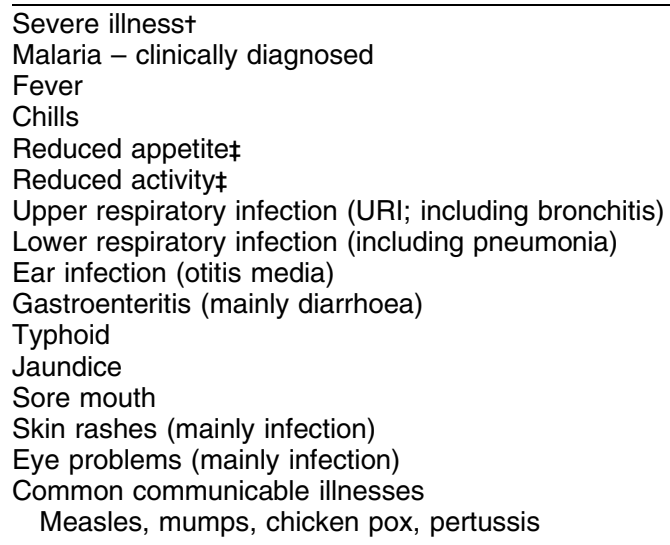

tIncludes: malaria, fever, chills, diarrhoea with $>3$ watery stools per day, lower respiratory infection (pneumonia), typhoid, jaundice, and illnesses accompanied by reduced food intake and/or physical activity and being bedridden. flndicators of severity.

the child on the day of the home visit and in the six preceding days. If the child was ill at home, specified visual observations of the child were made and recorded. Forms contained signs and symptoms organized by general non-specific and specific categories, comprising an illness category or clinical diagnosis. Familiar vernacular terms for common diseases were used. Morbidity outcomes are listed in Table 2, consisting of signs and symptoms found in commonly prevalent conditions. Reduced activity, being bedridden, having anorexia and fever were included as indicators of severe illness.

The morbidity interview form was translated into the local language (Kiembu) and back-translated to English. Bilingual enumerators completed the forms in English to facilitate quality checks and data entry. The supervising nurse was consulted about puzzling findings or possible serious illness (i.e. pneumonia, dehydration, convulsions, etc.) and promptly visited the child to determine if a physician evaluation and possible health facility referral were needed.

Morbidity quality control measures included intensive preliminary and ongoing training of enumerators by the physician, clinical officer and supervisory nurse, and re-interviews by the lead enumerator and nurse several hours later on $5 \%$ of interviews. Percentage agreement on specific findings and general categories of illness was 95\%. Medications and visits to a health facility were verified by available clinic or hospital cards. All forms were checked daily in the field by the lead morbidity enumerator for immediate correction of errors and/or missing data. Data were entered into a computer database. Ranges were printed out to enable checking for potential errors.

For health and ethical reasons, children with severe anaemia $(\mathrm{Hb} \leq 7 \cdot 0 \mathrm{~g} / \mathrm{dl}$ in the absence of malaria) were initially treated with oral ferrous sulfate for $30 \mathrm{~d}$ and if they showed no positive $\mathrm{Hb}$ response after one month, were referred for further studies and treatment. Children with suspected malaria were referred to the health centre for testing and treatment. All children were 'dewormed' every 6-8 months with mebendazole $(500 \mathrm{mg})$ to eradicate helminths. If a death occurred in a study child, the physician and/or nurse visited the home to carry out a 'verbal autopsy' and/or the clinic or hospital, to attempt to determine cause of death.

\section{Housebold and family information}

The household census, described previously ${ }^{(47)}$, was conducted at baseline. A crowding score was calculated by dividing the number of people regularly living in the 
household by the number of rooms per household. Kitchens were classified as indoor or outdoor. Main water source and latrine type and usage were determined. The socio-economic status (SES) score, described in previous publications, was developed for the study population ${ }^{(47)}$. Maternal literacy and writing level were assessed using graded material (Ministry of Education, Kenya). Maternal highest school grade completed was recorded.

\section{Nutrition measures}

Food intake and anthropometry, including quality control measures, were assessed at baseline and longitudinally according to methods described in detail elsewhere ${ }^{(47)}$. Briefly, food intake was measured by semi-quantitative $24 \mathrm{~h}$ recalls from the mother and the child, if present. Data from three consecutive visits, 2-3 weeks apart, were averaged to provide usual food intake at baseline ${ }^{(47)}$. Height, weight, head and arm circumferences, and triceps and subscapular skinfold thicknesses were measured by enumerators working in pairs, with results averaged ${ }^{(56)}$. Food intake and anthropometry were obtained monthly during the first year for Cohort I and every other month thereafter for both cohorts.

\section{Statistical methods}

ANOVA was used for continuous variables and a $\chi^{2}$ test of independence was used for categorical variables to detect significant differences among feeding groups at baseline. The fifteen morbidity outcomes are all binary outcomes (present/absent) and repeated observations within a subject are correlated. Therefore a logistic model with subject-specific random intercepts, a particular example of a generalized linear mixed model (GLMM), was fit to each outcome with the SAS glimmix macro ${ }^{(57)}$. Age at baseline and gender were included in all models to adjust for differences in the mix of children across treatment groups. We included separate fixed intercepts for each school; feeding group intercepts were estimated as the average of the effects for the three schools for each feeding group; we also included feeding group by time interactions. Because there was a strong seasonal pattern in morbidity outcomes, we included $\sin (2 \pi \times$ time $)$ and $\cos (2 \pi \times$ time $)$ terms in all models to model seasonal effects with time measured in years; additional higher-frequency sine and cosine terms were not needed to fit the data well. We calculated pairwise comparisons among the feeding group slopes. The model estimated slopes on the logit scale for each treatment group and we also estimated pairwise differences between feeding group slopes. For all morbidities, we plotted the estimated probability of morbidity outcome (PMO) by treatment group for a male child with mean age and median random effect of 0 at times from baseline to 2 years.

\section{Etbics}

The study was conducted according to the Declaration of Helsinki. All procedures involving human subjects were approved by the UCLA Human Subjects Protection Committee, the Ethics Committee of the University of Nairobi, School of Medicine, and the Kenya Office of the President. Witnessed and formally recorded verbal informed consent was obtained from all parents. Oral witnessed assent from the children, teachers and principals was also obtained. Community leaders and members assented by voice vote at several community-wide meetings.

\section{Results}

\section{Baseline findings}

No significant differences between groups were seen for household SES, maternal reading level, school years completed by the mother or children's school attendance. Baseline characteristics of the children and baseline nutrient intake data for the children are presented in Tables 3 and 4 . Mean age was 7·3 (SD 1·1) years. Baseline measures of anaemia and micronutrients are presented in Table 5. Children's immunization coverage was $\sim 70 \%$ for measles, polio, BCG (tuberculosis) and DPT (diphtheria, pertussis, tetanus). Eight per cent of families fetched drinking water from rivers and streams. Outdoor kitchens were used in $80 \cdot 8 \%$ of households. Crowding in the

Table 3 Baseline characteristics by study group (Cohorts I and II combined)

\begin{tabular}{|c|c|c|c|c|c|c|c|c|}
\hline & \multicolumn{2}{|c|}{ Plain Githeri ( $n$ 247) } & \multicolumn{2}{|c|}{ Milk ( $n$ 251) } & \multicolumn{2}{|c|}{ Meat ( $n$ 192) } & \multicolumn{2}{|c|}{ Control (n 212) } \\
\hline & Mean & SD & Mean & SD & Mean & SD & Mean & SD \\
\hline Male gender (\%) & $39 \cdot 0$ & & $51 \cdot 0$ & & $54 \cdot 0$ & & $45 \cdot 0$ & \\
\hline SES (total score) & $88 \cdot 1$ & $18 \cdot 9$ & $87 \cdot 4$ & $29 \cdot 6$ & $88 \cdot 7$ & $14 \cdot 9$ & $85 \cdot 9$ & $20 \cdot 3$ \\
\hline School attendance (\% days school open) & $83 \cdot 0$ & $15 \cdot 0$ & $83 \cdot 0$ & $13 \cdot 0$ & $86 \cdot 0$ & $14 \cdot 0$ & $84 \cdot 0$ & $17 \cdot 0$ \\
\hline Maternal reading levelt & $8 \cdot 46$ & $4 \cdot 69$ & $7 \cdot 66$ & $4 \cdot 74$ & $6 \cdot 90$ & $5 \cdot 34$ & $7 \cdot 45$ & $5 \cdot 03$ \\
\hline School completed by mother (years) & $6 \cdot 77$ & 3.35 & $6 \cdot 74$ & $3 \cdot 25$ & $5 \cdot 77$ & $2 \cdot 95$ & $7 \cdot 57 \ddagger$ & 3.53 \\
\hline Age (months) & $88 \cdot 3 \ddagger$ & $15 \cdot 8$ & $91 \cdot 3 \S$ & $18 \cdot 7$ & $94 \cdot 0 \S, \|$ & $14 \cdot 6$ & $86 \cdot 6 \ddagger$, & $13 \cdot 0$ \\
\hline Height $(\mathrm{cm})$ & $114 \cdot 3 \ddagger$ & $6 \cdot 3$ & $115 \cdot 6$ & $6 \cdot 2$ & $116 \cdot 6 \S, \|$ & $6 \cdot 3$ & $114 \cdot 6 \ddagger$ & $5 \cdot 8$ \\
\hline Weight (kg) & $19 \cdot 6 \ddagger$ & $2 \cdot 7$ & $19 \cdot 9$ & $2 \cdot 6$ & $20 \cdot 3$ & $2 \cdot 9$ & $19 \cdot 6$ & $2 \cdot 4$ \\
\hline
\end{tabular}

SES, socio-economic status.

tBased on the reading levels for each grade in the district primary schools.

$\ddagger$ Significantly different from the Meat group $(P<0 \cdot 05)$.

$\S$ Significantly different from the Control group $(P<0.05)$.

$\|$ Significantly different from the Plain Githeri group $(P<0.05)$.

- Significantly different from the Milk group $(P<0.05)$. 
Table 4 Baseline daily nutrient intakes by study group (Cohorts I and II combined)

\begin{tabular}{|c|c|c|c|c|c|c|c|c|c|}
\hline \multirow[b]{2}{*}{ Nutrient } & \multicolumn{2}{|c|}{ Plain Githeri ( $n$ 247) } & \multicolumn{2}{|c|}{ Milk ( $n$ 251) } & \multicolumn{2}{|c|}{ Meat ( $n$ 192) } & \multicolumn{2}{|c|}{ Control (n 212) } & \multirow[b]{2}{*}{$P$ valuet } \\
\hline & Mean & SD & Mean & SD & Mean & SD & Mean & SD & \\
\hline \multicolumn{10}{|l|}{ Energy } \\
\hline $\mathrm{kJ}$ & $7537 \cdot 7 \ddagger, \S$ & $2605 \cdot 4$ & $6738 \cdot 6 \|$ & $2238 \cdot 7$ & $7101 \cdot 1$ & $2256 \cdot 3$ & $6907 \cdot 3 \|$ & $2415 \cdot 7$ & 0.0028 \\
\hline kcal & $1800 \cdot 7 \ddagger, \S$ & $622 \cdot 4$ & $1609 \cdot 8 \|$ & $534 \cdot 8$ & $1696 \cdot 4$ & $539 \cdot 0$ & $1650 \cdot 1 \|$ & $577 \cdot 1$ & 0.0028 \\
\hline Protein (g) & $59 \cdot 1 \ddagger, \S$ & $32 \cdot 9$ & $49 \cdot 8 \|$, & $18 \cdot 6$ & $57 \cdot 1 \S$ & $26 \cdot 7$ & $51 \cdot 4 \|$ & $20 \cdot 3$ & $<0.0001$ \\
\hline Vitamin $\mathrm{B}_{12}(\mathrm{mg})$ & 0.46 & 0.64 & 0.41 & 0.39 & $0 \cdot 34 \ddagger$ & 0.46 & 0.52 & 0.55 & 0.0072 \\
\hline $\mathrm{Ca}(\mathrm{mg})$ & $278 \cdot 5$ & $144 \cdot 3$ & $250 \cdot 7$ & $113 \cdot 4$ & $252 \cdot 3$ & $115 \cdot 3$ & $279 \cdot 2$ & $149 \cdot 1$ & 0.0232 \\
\hline Available $\mathrm{Fe}(\mathrm{mg})$ & $1 \cdot 46 \ddagger, \S$ & 0.79 & $1 \cdot 21 \|$, & 0.59 & $1 \cdot 44 \ddagger, \S$ & 0.64 & $1 \cdot 25 \|$, & 0.62 & $<0.0001$ \\
\hline Available Zn (mg) & $1.06 \S$ & 0.52 & $0.93 \|$, & 0.36 & $1 \cdot 12 \S$ & 0.63 & 1.02 & 0.66 & 0.0033 \\
\hline
\end{tabular}

$+P$ value of ANOVA testing the equivalence of means in the four intervention groups.

$\ddagger$ Significantly different from the Control group $(P<0.05)$.

§Significantly different from the Milk group $(P<0.05)$.

IISignificantly different from the Plain Githeri group $(P<0.05)$.

$\checkmark$ Significantly different from the Meat group $(P<0.05)$.

Table 5 Baseline prevalence of anaemia and selected low micronutrient values by study group (Cohort I) $\dagger$

\begin{tabular}{|c|c|c|c|c|}
\hline & Meat $(n$ 126) & Milk (n 136) & Plain Githeri ( $n$ 133) & Control ( $n$ 124) \\
\hline & $\%$ & $\%$ & $\%$ & $\%$ \\
\hline Anaemia $(\mathrm{Hb}<11.5 \mathrm{~g} / \mathrm{dl})$ & $51 \cdot 6$ & $46 \cdot 3$ & $49 \cdot 6$ & $48 \cdot 4$ \\
\hline Plasma ferritin $<15 \mu \mathrm{g} / \mathrm{l}$ & $2 \cdot 4$ & $10 \cdot 9$ & 1.5 & $10 \cdot 7$ \\
\hline Serum $\mathrm{Fe}<9.0 \mu \mathrm{mol} / \mathrm{l}$ & $63 \cdot 9$ & $44 \cdot 0$ & $47 \cdot 1$ & $56 \cdot 1$ \\
\hline Serum $\mathrm{Zn}<10.7 \mu \mathrm{mol} / \mathrm{l}$ & $61 \cdot 5$ & $70 \cdot 1$ & $64 \cdot 0$ & $66 \cdot 7$ \\
\hline \multicolumn{5}{|l|}{ Vitamin $\mathrm{B}_{12}$ deficiency } \\
\hline Severe (plasma $\left.B_{12}<125 \mathrm{pmol} / \mathrm{l}\right)$ & $46 \cdot 8$ & $30 \cdot 6$ & $25 \cdot 0$ & $19 \cdot 7$ \\
\hline Moderate (plasma $\left.\mathrm{B}_{12} 125-221 \mathrm{pmol} / \mathrm{l}\right)$ & $33 \cdot 9$ & $41 \cdot 0$ & $37 \cdot 1$ & $38 \cdot 5$ \\
\hline \multicolumn{5}{|l|}{ Vitamin A deficiency } \\
\hline Severe (plasma retinol $<0.35 \mu \mathrm{mol} / \mathrm{l})$ & $31 \cdot 3$ & $23 \cdot 9$ & $16 \cdot 7$ & $17 \cdot 5$ \\
\hline Moderate (plasma retinol $0.35-0.70 \mu \mathrm{mol} / \mathrm{l})$ & $67 \cdot 6$ & $65 \cdot 0$ & $66 \cdot 7$ & $75 \cdot 7$ \\
\hline
\end{tabular}

Data from Siekmann et al. ${ }^{(52)}$.

tBiochemical analyses were not performed for Cohort II due to funding constraints.

Table 6 Baseline frequency of morbidity outcomes for all groups combined and by study group

\begin{tabular}{|c|c|c|c|c|c|c|}
\hline & Total & Plain Githeri ( $n$ 247) & Milk ( $n$ 251) & Meat (n 192) & Control (n 212) & \\
\hline Morbidity outcome & $\%$ & $\%$ & $\%$ & $\%$ & $\%$ & $P$ valuet \\
\hline All illnesses (mild and severe) & $61 \cdot 9$ & $59 \cdot 4$ & $60 \cdot 1$ & $61 \cdot 2$ & $67 \cdot 5$ & 0.29 \\
\hline Severe illness only $\ddagger$ & $20 \cdot 4$ & $22 \cdot 6$ & $20 \cdot 2$ & $21 \cdot \overline{3}$ & $17 \cdot 5$ & 0.60 \\
\hline Malaria & $10 \cdot 8$ & $13 \cdot 8$ & $7 \cdot 8$ & $14 \cdot 4$ & $7 \cdot 8$ & 0.03 \\
\hline Fever & $13 \cdot 1$ & $16 \cdot 7$ & $10 \cdot 3$ & $13 \cdot 3$ & $12 \cdot 1$ & $0 \cdot 20$ \\
\hline Chills & $9 \cdot 1$ & $11 \cdot 3$ & $7 \cdot 8$ & $9 \cdot 6$ & $7 \cdot 8$ & 0.50 \\
\hline Poor appetite & $13 \cdot 8$ & $17 \cdot 6$ & $10 \cdot 1$ & $12 \cdot 8$ & $14 \cdot 1$ & $0 \cdot 15$ \\
\hline Reduced activity & $13 \cdot 2$ & $15 \cdot 9$ & $11 \cdot 5$ & $12 \cdot 8$ & $12 \cdot 6$ & 0.53 \\
\hline Upper respiratory infection & $32 \cdot 5$ & $27 \cdot 2$ & $35 \cdot 4$ & $26 \cdot 6$ & $40 \cdot 8$ & 0.004 \\
\hline Ear infection & $3 \cdot 2$ & $2 \cdot \overline{1}$ & 3.7 & 3.2 & 3.9 & 0.69 \\
\hline Gastroenteritis $\S$ & $11 \cdot 9$ & $11 \cdot 7$ & $10 \cdot 3$ & $13 \cdot 3$ & $12 \cdot 6$ & $0 \cdot 79$ \\
\hline Typhoid & 0.68 & 0.84 & 0.41 & 0.53 & 0.97 & $0 \cdot 88$ \\
\hline Jaundice & $7 \cdot 7$ & $7 \cdot 5$ & $7 \cdot 0$ & $12 \cdot 8$ & 3.9 & 0.01 \\
\hline Sore mouth & $11 \cdot 1$ & $10 \cdot 9$ & $10 \cdot 3$ & $11 \cdot 2$ & $12 \cdot 1$ & 0.94 \\
\hline Skin infection & $25 \cdot 2$ & $27 \cdot 6$ & $24 \cdot 3$ & $26 \cdot 1$ & $22 \cdot 8$ & 0.67 \\
\hline Eye problems & $2 \cdot 4$ & $0 \cdot 8$ & $2 \cdot 5$ & $4 \cdot 3$ & $2 \cdot 4$ & $0 \cdot 15$ \\
\hline
\end{tabular}

t $P$ value from $\chi^{2}$ test for the equivalence of probabilities in the four intervention groups.

¥Severity based on illness type and accompanying chills, fever, reduced activity, being bedridden and reduced appetite.

\$Mainly diarrhoea.

Cohort I sample was $2 \cdot 3(\mathrm{SD} 1 \cdot 2)$ persons per room ${ }^{(58)}$. Although $60 \%$ of households had latrines, young children did not use these. Baseline stool examinations showed prevalence of Entamoeba bystolytica (21.4\%),
Giardia lamblia (12.5\%), hookworm (2\%) and Ascaris spp. $(3 \%)^{(47)}$. Few households had bed nets.

The baseline frequency of morbidities is summarized in Table 6. At baseline, $61 \cdot 9 \%$ of children had an illness, 
Table 7 Parameter estimates by age and gender (boy) for baseline morbidity outcomes

\begin{tabular}{lcc}
\hline Effect outcome & Age & Gender (boy) \\
\hline Total illness $v$. no illness & $-0 \cdot 0584^{\star}$ & $0 \cdot 1759^{\star *}$ \\
Severe $v$. mild and no illness & $-0 \cdot 0896^{\star *}$ & $0 \cdot 1183$ \\
Malaria & $-0 \cdot 1100^{\star *}$ & $-0 \cdot 0664$ \\
Fever & $-0 \cdot 0661$ & $-0 \cdot 1136$ \\
Chills & $-0 \cdot 0112$ & $-0 \cdot 0531$ \\
Poor appetite & $-0 \cdot 1244^{\star \star}$ & $-0 \cdot 0812$ \\
Reduced activity & $-0 \cdot 0764^{*}$ & $-0 \cdot 1363$ \\
Upper respiratory infection & $-0 \cdot 1014^{\star * *}$ & $-0 \cdot 0012$ \\
Ear infection & $0 \cdot 1244$ & $-0 \cdot 3286$ \\
Gastroenteritist & $0 \cdot 0256$ & $-0 \cdot 2579^{\star *}$ \\
Typhoid & $-0 \cdot 0241$ & $0 \cdot 3314^{\star *}$ \\
Jaundice & $0 \cdot 1186$ & $-0 \cdot 8772^{\star}$ \\
Sore mouth & $-0 \cdot 1041^{*}$ & $0 \cdot 2389^{\star}$ \\
Skin infection & $0 \cdot 0056$ & $0 \cdot 2687^{\star *}$ \\
Eye problems & $-0 \cdot 1051$ & $0 \cdot 0408$ \\
\hline
\end{tabular}

${ }^{\star} P \leq 0.05,{ }^{* *} P \leq 0.01,{ }^{* * *} P \leq 0.001$.

+Mainly diarrhoea.

mainly infections, with $20 \cdot 4 \%$ having severe illness. The leading illness categories reported, in descending order, were URI (though with few cases of pneumonia), skin infections, poor appetite, reduced activity, fever, gastroenteritis (mainly diarrhoea), sore mouth and clinical malaria diagnosed and confirmed by testing in a health facility. Five children died during the study from malaria, hepatitis and presumed sepsis.

\section{Baseline age and gender effects on morbidity}

With increasing baseline age, the PMO for total illness and severe illness, malaria, poor appetite, reduced activity, URI and sore mouth showed statistically significant decreases (Table 7).

Boys had significantly higher PMO rates than girls for total illness, sore mouth, skin infections and typhoid fever. In contrast, boys had significantly lower PMO for episodes of gastroenteritis and jaundice than the girls (Table 7).

\section{Intervention findings}

Seasonal effects

For most morbidity outcomes, significant and strong seasonal effects were apparent, with significant peaks and valleys. The peak for gastroenteritis prevalence was in March and early April, coinciding with the beginning of the rainy season (Fig. 2). The peaks for malaria (Fig. 3), poor appetite, fever and reduced activity were seen in March and April, coinciding with the long rains. For respiratory and ear infections, the peaks were noted in May (Fig. 4), coinciding with the beginning of the cold and drier season. Severe illness peaked in the rainy season (data not shown).

\section{Morbidity outcomes by intervention group}

Rates of change in PMO for each morbidity outcome by feeding group are presented in Table 8. Except for sore mouth, which showed significant increases in all except the Plain Githeri group, every significant result showed a

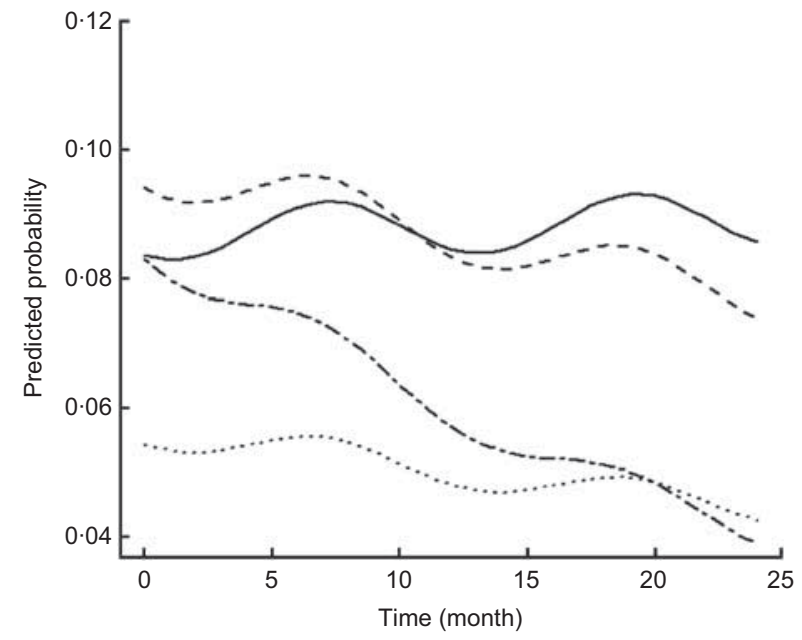

Fig. 2 Estimated trends of gastroenteritis (mainly diarrhoea) over time (for boys at median age of $7 \cdot 22$ years old) according to study group (- Control; - - -, Plain Githeri; - - Meat; ---, Milk)

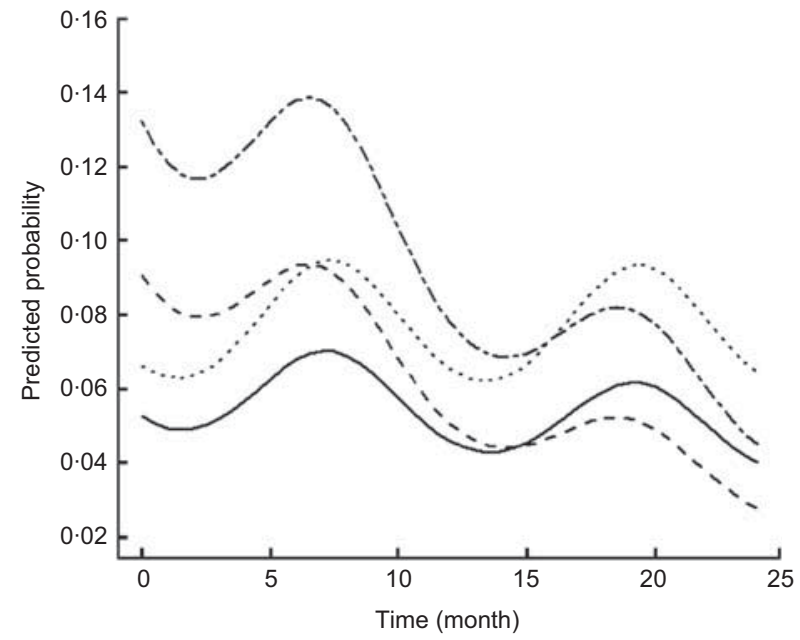

Fig. 3 Estimated trends of malaria over time (for boys at median age of $7 \cdot 22$ years old) according to study group ( Control; - - -, Plain Githeri; - - -, Meat; - --, Milk)

decrease in PMO. The only outcome that showed no significant decreases or increases was eye problems. The Meat group had a significant decrease in every morbidity outcome except sore mouth and eye problems. The Plain Githeri group showed significant decreases in total illness, severe illness, malaria, fever, chills, poor appetite, reduced activity and URI, but not in other morbidities. The Milk group showed significant decreases only for poor appetite and URI, as did the Control group. The Control group also showed significant decreases in fever and ear infection.

Differences in rates of change in PMO were seen by feeding group (Table 9). For most outcomes and for total and severe illness, the Plain Githeri and Meat groups showed the steepest statistically significant declines in slopes for PMO in comparison to the Milk and Control 
groups (Tables 9 and 10). The declines in the Plain Githeri group were not significantly different from those in the Meat group except for jaundice and sore mouth, where the Plain Githeri group fared better. The Meat group had significantly less malaria, gastroenteritis and typhoid than the Control group. The Milk group was not significantly different from the Control group except for skin infections, which were significantly fewer in the Control group. The Plain Githeri group had significantly less total illness, severe illness, malaria, chills, poor appetite, reduced activity and sore mouth than the Control group.

\section{Discussion}

We had hypothesized that children in the Meat and Milk groups would have the greatest reductions in PMO.

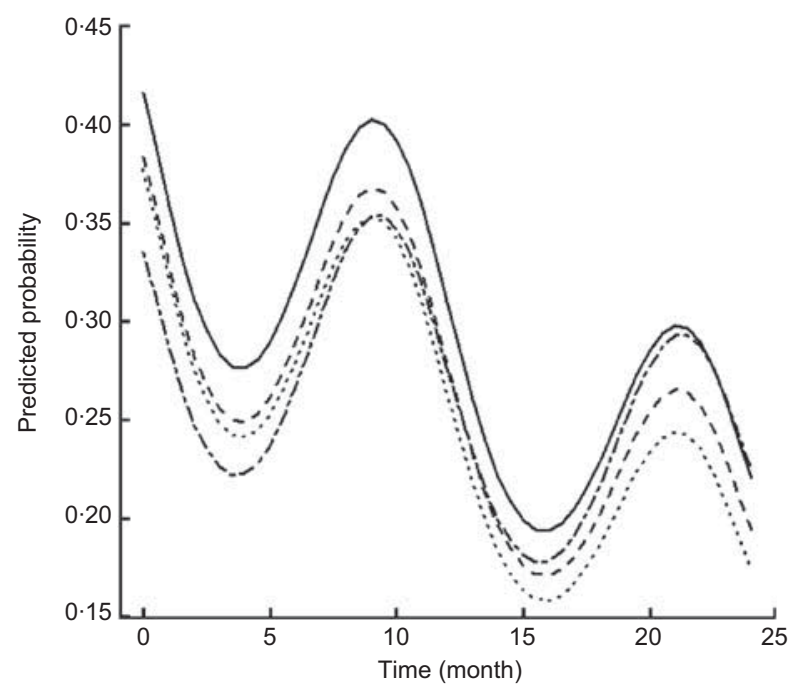

Fig. 4 Estimated trends of upper respiratory infection over time (for boys at median age of 7.22 years old) according to study group ( - , Control; - - - , Plain Githeri; _ - - Meat; - - -, Milk)
The higher content of bioavailable Fe and $\mathrm{Zn}$ and vitamin $\mathrm{B}_{12}$ in the meat snack and the higher levels of vitamin $\mathrm{A}$ and $\mathrm{B}_{12}$ in the UHT milk were thought to promote improved cell-mediated immunity. The Meat githeri clearly conferred an advantage in reduction of gastroenteritis, typhoid, jaundice and clinical malaria with its accompanying symptoms (fever and chills). The greatest reduction in PMO for gastroenteritis and typhoid in the Meat group may be attributed to the greater concentrations of bioavailable $\mathrm{Zn}$ and $\mathrm{Fe}$, and vitamin $\mathrm{B}_{12}$ in meat. $\mathrm{Zn}$ supplementation has been shown to prevent and successfully treat chronic diarrhoea $(>2$ weeks) in malnourished children ${ }^{(31,32,59)}$. In our sub-study of antibody titres to Helicobacter pylori and rotavirus, found to be the main causes of gastroenteritis in the area, the Meat group showed significant increases in protective IgM antibody responses ${ }^{(60)}$. This could also be a contributory mechanism by which the Meat group showed less gastrointestinal morbidity ${ }^{(60)}$. The reduction in clinical malaria in the Meat group may be related to improved $\mathrm{Zn}$ intake, which has been shown reduce the number of $P$. falciparum malaria febrile malarial episodes ${ }^{(35)}$.

All groups showed declines in PMO for URI, and differences among the groups were not significant except for the Milk group decreasing significantly more than the Meat group. This may partly attributed to the higher vitamin A content in milk. The Control and Milk groups fared worse than the Plain Githeri group for total and severe illnesses and several morbidities. The Control group did not receive the additional energy and consumed lower amounts of protein, bioavailable $\mathrm{Fe}$ and $\mathrm{Zn}$, vitamin $\mathrm{B}_{12}$, riboflavin and vitamin A than those receiving the school snacks.

The Plain Githeri group surprisingly showed a significantly greater decline in slopes for many morbidities compared with the Milk and Control groups, though not compared with the Meat group. A probable explanation is that the commercial cooking oil added to equalize the energy content of snacks was fortified with vitamin A by

Table 8 Slope estimates (time in months) on logit scale for morbidities by intervention group

\begin{tabular}{|c|c|c|c|c|}
\hline Morbidity outcome & Meat & Milk & Plain Githeri & Control \\
\hline Total illness v. no illness & $-0 \cdot 0167^{\star}$ & -0.0058 & $-0.0260^{\star \star \star}$ & -0.0089 \\
\hline Severe $v$. mild and no illness & $-0.0275^{\star \star}$ & -0.0088 & $-0.0479^{\star \star \star}$ & -0.0118 \\
\hline Malaria & $-0.0489^{\star \star \star}$ & -0.0012 & $-0.0521^{\star \star \star}$ & -0.0118 \\
\hline Fever & $-0.0517^{\star \star \star}$ & -0.0179 & $-0.0556^{\star \star \star}$ & $-0.0298^{\star \star}$ \\
\hline Chills & $-0.0431^{\star \star}$ & -0.0166 & $-0.0578^{\star \star \star}$ & -0.0205 \\
\hline Poor appetite & $-0.0464^{\star \star \star}$ & $-0.0300^{\star *}$ & $-0.0734^{\star * \star}$ & $-0.0219^{*}$ \\
\hline Reduced activity & $-0.0388^{\star \star}$ & -0.0151 & $-0.0672^{\star \star \star}$ & -0.0126 \\
\hline Upper respiratory infection & $-0.0231^{\star *}$ & $-0.0439^{\star \star \star}$ & $-0.0397^{\star \star \star}$ & $-0.0384^{\star * *}$ \\
\hline Ear infection & $-0.0455^{\star}$ & -0.0132 & -0.0393 & $-0.0563^{\star \star}$ \\
\hline Gastroenteritist & $-0.0335^{\star}$ & -0.0108 & -0.0110 & $0 \cdot 0011$ \\
\hline Typhoid & $-0.0429^{\star \star}$ & -0.0268 & -0.0274 & -0.0061 \\
\hline Jaundice & $-0 \cdot 1482^{*}$ & -0.0578 & 0.0148 & -0.0272 \\
\hline Sore mouth & $0.0534^{\star \star *}$ & $0.0417^{* * *}$ & 0.0140 & $0.0586^{\star * \star}$ \\
\hline Skin infection & $-0.0217^{\star \star}$ & 0.0080 & -0.0117 & -0.0113 \\
\hline Eye problems & -0.0138 & -0.0050 & 0.0160 & 0.0133 \\
\hline
\end{tabular}

Negative values imply decreases in illness over time.

${ }^{\star} P \leq 0.05,{ }^{\star \star} P \leq 0.01,{ }^{\star \star *} P \leq 0.001$.

tMainly diarrhoea. 
Table 9 Pairwise comparisons of slopes between intervention groups for selected morbidity outcomes

\begin{tabular}{|c|c|c|c|c|c|c|}
\hline & $\begin{array}{l}\text { Meat } v . \\
\text { Plain Githeri }\end{array}$ & $\begin{array}{l}\text { Meat } v \text {. } \\
\text { Control }\end{array}$ & $\begin{array}{l}\text { Meat } v . \\
\text { Milk }\end{array}$ & $\begin{array}{l}\text { Milk } v . \\
\text { Plain Githeri }\end{array}$ & $\begin{array}{l}\text { Milk v. } \\
\text { Control }\end{array}$ & $\begin{array}{c}\text { Plain Githeri v. } \\
\text { Control }\end{array}$ \\
\hline Total illness $v$. no illness & 0.0094 & -0.0078 & -0.0109 & $0.0203^{\star}$ & 0.0031 & $-0.0172^{\star}$ \\
\hline Severe $v$. mild and no illness & 0.0204 & $-0 \cdot 0157$ & $-0 \cdot 0187$ & $0.0391^{\star *}$ & $0 \cdot 0030$ & $-0.0361^{\star *}$ \\
\hline Malaria & 0.0032 & $-0.0371^{*}$ & $-0.0476^{\star \star}$ & $0.0509^{* *}$ & 0.0105 & $-0.0403^{*}$ \\
\hline Fever & 0.0038 & -0.0220 & $-0.0338^{\star}$ & $0.0376^{\star}$ & 0.0118 & -0.0258 \\
\hline Chills & 0.0147 & $-0 \cdot 0225$ & -0.0265 & $0 \cdot 0412^{*}$ & $0 \cdot 0040$ & $-0.0372^{\star}$ \\
\hline Poor appetite & 0.0270 & -0.0244 & -0.0164 & $0.0434^{\star \star}$ & -0.0080 & $-0.0514^{\star *}$ \\
\hline Reduced activity & 0.0284 & -0.0262 & -0.0237 & $0.0521^{\star \star \star}$ & -0.0025 & $-0.0546^{\star \star \star}$ \\
\hline Upper respiratory infection & 0.0166 & 0.0154 & $0.0208^{*}$ & -0.0042 & -0.0054 & -0.0012 \\
\hline Ear infection & -0.0062 & 0.0108 & -0.0323 & 0.0261 & 0.0431 & 0.0170 \\
\hline Gastroenteritist & -0.0226 & $-0.0346^{*}$ & $-0 \cdot 0228$ & 0.0002 & -0.0119 & $-0 \cdot 0121$ \\
\hline Typhoid & -0.0155 & $-0.0368^{\star}$ & -0.0161 & 0.0007 & -0.0207 & -0.0213 \\
\hline Jaundice & $-0 \cdot 1630^{\star}$ & $-0 \cdot 1210$ & -0.0904 & -0.0726 & -0.0306 & 0.0420 \\
\hline Sore mouth & $0.0394^{\star \star}$ & -0.0052 & 0.0118 & $0.0276^{*}$ & $-0 \cdot 0170$ & $-0.0446^{\star \star \star}$ \\
\hline Skin infection & $-0 \cdot 0100$ & $-0 \cdot 0104$ & $-0.0297^{\star \star}$ & $0.0196^{*}$ & $0 \cdot 0193^{*}$ & -0.0004 \\
\hline Eye problems & -0.0298 & -0.0271 & -0.0088 & -0.0210 & -0.0182 & 0.0027 \\
\hline
\end{tabular}

Negative values mean that the first group of the pair had a higher rate of decrease in morbidity outcome. Positive values mean that the second group of the pair had higher rate of decrease in the morbidity outcome.

${ }^{\star} P \leq 0 \cdot 05,{ }^{* \star} P \leq 0.01,{ }^{* *} P \leq 0 \cdot 001$.

tMainly diarrhoea.

Table 10 Summary of statistically significant changes in slopes for probability of morbidity outcomes

\begin{tabular}{ll}
\hline Outcome & Summary \\
\hline Total illness $v$. no illness & Plain Githeri $<$ Control, Milk \\
Severe $v$. mild or no illness & Plain Githeri $<$ Control, Milk \\
Malaria & Plain Githeri, Meat $<$ Control, Milk \\
Fever & Plain Githeri, Meat $<$ Milk \\
Chills & Plain Githeri $<$ Control, Milk \\
Poor appetite & Plain Githeri $<$ Control, Milk \\
Reduced activity & Plain Githeri $<$ Control, Milk \\
Upper respiratory infection & Milk $<$ Meat \\
Ear infection & No significant differences between the four groups \\
Gastroenteritis & Meat $<$ Control \\
Typhoid & Meat $<$ Control \\
Jaundice & Meat $<$ Plain Githeri \\
Sore mouth & Plain Githeri $<$ Meat, Control, Milk \\
Skin infection & Plain Githeri, Meat, Control $<$ Milk \\
Eye problems & No significant differences between the four groups \\
\hline
\end{tabular}

Here, '<' means a greater decrease over time or 'better'. For example, 'Meat $<$ Control' for malaria means that the rate of malaria in the Meat group dropped faster than the rate in the Control group.

the manufacturer and not labelled initially. Children in all groups showed evidence of vitamin A deficiency at baseline (Table 5). All three feeding groups received some of this fortified oil to equalize the energy content, but greater amounts were added to the Plain Githeri snack (Table 1). The retinol-fortified oil was the most likely reason for the impressive decline in PMO in the Plain Githeri group.

Although seasonality is an important covariate for morbidity, all groups were similarly affected by seasonal trends. Gastroenteritis was most common during rainy seasons. Respiratory diseases were most prevalent in the cold months. More fever and chills were observed during rainy seasons, presumably due to malaria. Even though two of the Meat schools were located close to residual swamps, which are known as breeding sites for Anopheles mosquitoes, the Meat group showed a negative
PMO slope for malaria and its accompanying signs and symptoms (Fig. 3).

The consistently higher rates of illnesses in boys compared with girls, particularly for mild illness, have been seen in a number of studies, including our previous Embu study $^{(61)}$. Higher prevalence of mild illness was observed in school-aged boys than girls of the same age; however, girls were more likely than boys to have more severe illnesses $^{(62)}$. This may reflect the greater time boys spent out in the community. Girls spent more time at home. For severe illnesses, boys may be favoured and preferentially taken to a health facility or health-care provider for treatment compared with girls.

Strengths of the present study include its cluster randomized longitudinal design with repeated measures conducted in the two cohorts; strict quality control, training and supervision of local enumerators; and excellent rapport 
with the community and field staff. Weaknesses of the study include the small number of schools per group as schools had to be accessible by road and have a certain number of children. Study participants were not blinded to the group feeding assignment, but they were blinded to study hypotheses, as were teachers and field staff.

This is the first cluster randomized, controlled feeding intervention study to analyse the contribution of the addition of ASF, particularly meat, on morbidity outcomes in addition to the previously demonstrated cognitive, behavioural and body composition improvements ${ }^{(47,63)}$. An unexpected and important outcome was the positive impact of the addition of a considerable amount of retinol to the Plain Githeri snacks, which demonstrated the value of such fortification in reducing morbidity. These findings are relevant to school-aged children in economically disadvantaged countries where little or no school feeding occurs. School-aged children in these areas tend to be relatively neglected by public health efforts compared with the $<5$-year-old age group. School feeding is far from universal in such areas, and many children do not regularly attend school. Fortification of fats would be a reasonable approach to reduce morbidity in children, plus adding a wide variety of local ASF. Raising small animals and access to affordable fortified foods in local markets may also help to reduce child morbidity.

\section{Acknowledgements}

Sources of funding: This study was supported by the Global Livestock Collaborative Research Support Program (GL-CRSP), US Agency for International Development (DAN-1328-G-00-0046-00), with partial funding from the African Study Center (UCLA) and the National Cattleman's Beef Association (PCE-G-98-00036-00). Conflicts of interest: None. Authors' contributions: C.G.N. was the Principal Investigator, was responsible for the study design, oversaw overall research activities, and helped guide the statistical analysis and writing of the manuscript. N.O.B. was the Kenyan Principal Investigator and directed the overall research activities in the field, particularly morbidity data collection. R.E.W. designed the statistical analysis and edited the manuscript. L.J. performed the statistical analysis and participated in the writing of the manuscript. Acknowledgements: The authors thank Suzanne Murphy and Connie Gewa for food intake data and analysis; Dr Don Guthrie, Emeritus Professor of Biostatistics at UCLA, for his involvement in the initial statistical design of the study; Natalie Drorbaugh and Maria Pia Chaparro for literature review, drafting and editing of the manuscript; and Jonathan Siekmann, Erin Reid McLean and Lindsay Allen for carrying out laboratory analyses. Most importantly, they wish to acknowledge the field staff (enumerators) and the excellent cooperation of the schools, children and families who participated in the study.

\section{References}

1. Bryce J, Boschi-Pinto C, Shibuya K et al. (2005) WHO estimates of the causes of death in children. Lancet 365, 1147-1152.

2. Caulfield LE, de Onis M, Blossner M et al. (2004) Undernutrition as an underlying cause of child deaths associated with diarrhea, pneumonia, malaria, and measles. Am J Clin Nutr 80, 193-198.

3. Caulfield LE, Richard SA \& Black RE (2004) Undernutrition as an underlying cause of malaria morbidity and mortality in children less than five years old. Am J Trop Med Hyg 71, 55-63.

4. Black RE, Morris SS \& Bryce J (2003) Where and why are 10 million children dying every year? Lancet 361, 2226-2234.

5. Murphy SP \& Allen LH (2003) Nutritional importance of animal source foods. J Nutr 133, 11 Suppl. 2, 3932S-3935S.

6. Peña M \& Bacallao J (2002) Malnutrition and poverty. Annu Rev Nutr 22, 241-253.

7. Black RE, Allen LH, Bhutta ZA et al. (2008) Maternal and child undernutrition: global and regional exposures and health consequences. Lancet 371, 243-260.

8. Scrimshaw NS \& SanGiovanni JP (1997) Synergism of nutrition, infection, and immunity: an overview. Am J Clin Nutr 66, issue 2, 464S-477S.

9. Neumann CG (1981) Malnutriton and infection. In Infection: The Physiologic and Metabolic Responses of the Host, pp. 319-357 [MC Powanda and PG Canonico, editors]. Amsterdam: Elsevier/North-Holland Biomedical Press.

10. Ross AC (1996) Vitamin A deficiency and retinoid repletion regulate the antibody response to bacterial antigens and the maintenance of natural killer cells. Clin Immunol Immunopathol 80, 3 Pt 2, S63-S72.

11. Prasad AS (2000) Effects of zinc deficiency on Th1 and Th2 cytokine shifts. J Infect Dis 182, Suppl. 1, S62-S68.

12. Funada U, Wada M, Kawata $\mathrm{T}$ et al. (2000) Changes in $\mathrm{CD}^{+} \mathrm{CD}^{-} / \mathrm{CD}^{-} \mathrm{CD}^{+}$ratio and humoral immune functions in vitamin $\mathrm{B}_{12}$-deficient rats. Int J Vitam Nutr Res $\mathbf{7 0}$, 167-171.

13. Bhaskaram P (2002) Micronutrient malnutrition, infection, and immunity: an overview. Nutr Rev 60, 5 Pt 2, S40-S45.

14. Ekiz C, Agaoglu L, Karakas Z et al. (2005) The effect of iron deficiency anemia on the function of the immune system. Hematol J 5, 579-583.

15. Juyal R, Osmamy M, Black RE et al. (2004) Efficacy of micronutrient fortification of milk on morbidity in preschool children and growth - a double blind randomised controlled trial. Asia Pac J Clin Nutr 13, Suppl., S44.

16. Baqui AH, Black RE, Arifeen SE et al. (2002) Effect of zinc supplementation started during diarrhoea on morbidity and mortality in Bangladeshi children: community randomised trial. BMJ 325, 1059.

17. Baqui AH, Zaman K, Persson LA et al. (2003) Simultaneous weekly supplementation of iron and zinc is associated with lower morbidity due to diarrhea and acute lower respiratory infection in Bangladeshi infants. $J$ Nutr 133, $4150-4157$.

18. Rahman MM, Vermund SH, Wahed MA et al. (2001) Simultaneous zinc and vitamin A supplementation in Bangladeshi children: randomised double blind controlled trial. BMJ 323, 314-318.

19. Imdad A, Herzer K, Mayo-Wilson E et al. (2010) Vitamin A supplementation for preventing morbidity and mortality in children from 6 months to 5 years of age. Cochrane Database Syst Rev issue 12, CD008524.

20. Imdad A, Yakoob MY, Sudfeld C et al. (2011) Impact of vitamin A supplementation on infant and childhood mortality. BMC Public Health 11, Suppl. 3, S20.

21. Haidar J, Tsegaye D, Mariam DH et al. (2003) Vitamin A supplementation on child morbidity. East Afr Med J 80, $17-21$. 
22. Chowdhury S, Kumar R, Ganguly NK et al. (2002) Effect of vitamin A supplementation on childhood morbidity and mortality. Indian J Med Sci 56, 259-264.

23. Shankar AH, Genton B, Semba RD et al. (1999) Effect of vitamin A supplementation on morbidity due to Plasmodium falciparum in young children in Papua New Guinea: a randomised trial. Lancet 354, 203-209.

24. Long KZ, Rosado JL, DuPont HL et al. (2007) Supplementation with vitamin A reduces watery diarrhoea and respiratory infections in Mexican children. Br J Nutr 97, 337-343.

25. Sempertegui F, Estrella B, Camaniero V et al. (1999) The beneficial effects of weekly low-dose vitamin A supplementation on acute lower respiratory infections and diarrhea in Ecuadorian children. Pediatrics 104, e1.

26. Humphrey JH, Agoestina T, Wu L et al. (1996) Impact of neonatal vitamin A supplementation on infant morbidity and mortality. J Pediatr 128, 489-496.

27. Fischer Walker CL \& Black RE (2007) Micronutrients and diarrheal disease. Clin Infect Dis 45, Suppl. 1, S73-S77.

28. Sazawal S, Jalla S, Mazumder S et al. (1997) Effect of zinc supplementation on cell-mediated immunity and lymphocyte subsets in preschool children. Indian Pediatr 34, 589-597.

29. Prasad AS (2009) Zinc: role in immunity, oxidative stress and chronic inflammation. Curr Opin Clin Nutr Metab Care 12, 646-652.

30. Bhandari N, Bahl R, Taneja S et al. (2002) Substantial reduction in severe diarrheal morbidity by daily zinc supplementation in young north Indian children. Pediatrics 109, e86.

31. Bhutta ZA, Bird SM, Black RE et al. (2000) Therapeutic effects of oral zinc in acute and persistent diarrhea in children in developing countries: pooled analysis of randomized controlled trials. Am J Clin Nutr $\mathbf{7 2}$ 1516-1522.

32. Fischer Walker C \& Black RE (2004) Zinc and the risk for infectious disease. Annu Rev Nutr 24, 255-275.

33. Penny ME, Marin RM, Duran A et al. (2004) Randomized controlled trial of the effect of daily supplementation with zinc or multiple micronutrients on the morbidity, growth, and micronutrient status of young Peruvian children. $A m J$ Clin Nutr 79, 457-465.

34. Bhandari N, Bahl R, Taneja S et al. (2002) Effect of routine zinc supplementation on pneumonia in children aged 6 months to 3 years: randomised controlled trial in an urban slum. BMJ 324, 1358.

35. Shankar AH, Genton B, Baisor $M$ et al. (2000) The influence of zinc supplementation on morbidity due to Plasmodium falciparum: a randomized trial in preschool children in Papua New Guinea. Am J Trop Med Hyg $\mathbf{6 2}$, 663-669.

36. Black RE (1998) Therapeutic and preventive effects of zinc on serious childhood infectious diseases in developing countries. Am J Clin Nutr 68, 2 Suppl., 476S-479S.

37. Oppenheimer SJ (2001) Iron and its relation to immunity and infectious disease. J Nutr 131, 2S-2, 616S-633S.

38. de Silva A, Atukorala S, Weerasinghe I et al. (2003) Iron supplementation improves iron status and reduces morbidity in children with or without upper respiratory tract infections: a randomized controlled study in Colombo, Sri Lanka. Am J Clin Nutr 77, 234-241.

39. Gera T \& Sachdev HPS (2002) Effect of iron supplementation on incidence of infectious illness in children: systematic review. BMJ 325, 1142.

40. Nyakeriga AM, Troye-Blomberg M, Dorfman JR et al. (2004) Iron deficiency and malaria among children living on the coast of Kenya. J Infect Dis 190, 439-447.

41. Berger J, Dyck JL, Galan P et al. (2000) Effect of daily iron supplementation on iron status, cell-mediated immunity, and incidence of infections in 6-36 month old Togolese children. Eur J Clin Nutr 54, 29-35.

42. Rivlin RS \& Dutta P (1995) Vitamin B (riboflavin): relevance to malaria and antioxidant activity. Nutr Today 30, 62-67.

43. Sazawal S, Black RE, Ramsan M et al. (2006) Effects of routine prophylactic supplementation with iron and folic acid on admission to hospital and mortality in preschool children in a high malaria transmission setting: communitybased, randomised, placebo-controlled trial. Lancet 367, 133-143.

44. English RM, Badcock JC, Giay T et al. (1997) Effect of nutrition improvement project on morbidity from infectious diseases in preschool children in Vietnam: comparison with control commune. BMJ 315, 1122-1125.

45. Sripaipan T, Schroeder DG, Marsh DR et al. (2002) Effect of an integrated nutrition program on child morbidity due to respiratory infection and diarrhea in northern Viet Nam. Food Nutr Bull 23, 70-77.

46. Yeudall F, Gibson RS, Kayira C et al. (2002) Efficacy of a multi-micronutrient dietary intervention based on haemoglobin, hair zinc concentrations, and selected functional outcomes in rural Malawian children. Eur J Clin Nutr 56, $1176-1185$.

47. Neumann CG, Bwibo NO, Murphy SP et al. (2003) Animal source foods improve dietary quality, micronutrient status, growth and cognitive function in Kenyan school children: background, study design and baseline findings. $J$ Nutr 133, 11 Suppl. 2, 3941S-3949S.

48. Murphy SP, Gewa C, Grillenberger M et al. (2007) Designing snacks to address micronutrient deficiencies in rural Kenyan schoolchildren. J Nutr 137, 1093-1096.

49. Murphy SP, Gewa C, Liang LJ et al. (2003) School snacks containing animal source foods improve dietary quality for children in rural Kenya. J Nutr 133, 11 Suppl. 2, 3950S-3956s.

50. Gewa C, Murphy SP, Bwibo NO et al. (2005) Assessment of Snack Acceptance During a School Feeding Intervention in Rural Kenya: Research Brief O5-O3-CNP. Davis, CA: Global Livestock Collaborative Research Support Program.

51. Gibson RS (2005) Clinical assessment. In Principles of Nutritional Assessment, 2nd ed., pp. 797-803. New York: Oxford University Press.

52. Siekmann JH, Allen LH, Bwibo NO et al. (2003) Kenyan school children have multiple micronutrient deficiencies, but increased plasma vitamin B-12 is the only detectable micronutrient response to meat or milk supplementation. J Nutr 133, 11 Suppl. 2, 3972S-3980S.

53. Carter J \& Orgenes E (1994) A Practical Laboratory Manual for Health Centers in Eastern Africa. Nairobi: African Medical and Research Foundation.

54. Bridges N, Darvin R \& Van Assendelft O (1987) Evaluation of a new system for hemoglobin measurement. Am Clin Prod Rev 4, 22-25.

55. Neumann CG, Bwibo NO, Siekmann JH et al. (2008) Comparison of blood smear microscopy to a rapid diagnostic test for in-vitro testing for $P$. falciparum malaria in Kenyan school children. East Afr Med J 85, 544-549.

56. Grillenberger M, Neumann CG, Murphy SP et al. (2003) Food supplements have a positive impact on weight gain and the addition of animal source foods increases lean body mass of Kenyan schoolchildren. J Nutr 133, 11 Suppl. 2, 3957S-3964S.

57. Weiss RE (2005) Modeling Longitudinal Data. New York: Springer.

58. Grillenberger M, Neumann CG, Murphy SP et al. (2006) Impact of Supplementation with Animal Source Foods on Morbidity of Rural Kenyan Schoolchildren. Wageningen: Wageningen University. 
59. Bhutta ZA, Black RE, Brown KH et al. (1999) Prevention of diarrhea and pneumonia by zinc supplementation in children in developing countries: pooled analysis of randomized controlled trials. Zinc Investigators' Collaborative Group. J Pediatr 135, 689-697.

60. Siekmann JH, Allen LH, Watnik MR et al. (2003) Titers of antibody to common pathogens: relation to food-based interventions in rural Kenyan schoolchildren. Am J Clin Nutr 77, 242-249.

61. Neumann CG \& Bwibo NO (1987) The Collaborative Research Support Program on Food Intake and Human Function, Kenya Project: Final Report. Los Angeles, CA: University of California, Los Angeles.
62. Neumann CG, Bwibo NO \& Sigman M (1992) Final Report Phase II: Functional Implications of Malnutrition, Kenya Project. Human Nutrition Collaborative Research Support Program. Los Angeles, CA: University of California, Los Angeles.

63. Neumann CG, Murphy SP, Gewa C et al. (2007) Meat supplementation improves growth, cognitive, and behavioral outcomes in Kenyan children. $J$ Nutr 137, $1119-1123$.

64. Neumann CG, Jiang L, Weiss RE et al. (2012) Meat supplementation increases arm muscle area in Kenyan schoolchildren. Br J Nutr (Epublication ahead of print version). 